\title{
Knowledge and Awareness About Haemophobia and Trypanophobia Among Dental Patients in Saveetha Dental Hospital
}

\author{
Bianca Princeton ${ }^{1}$, R. Gayatri Devi², and A. Jothi Priya ${ }^{3}$ \\ ${ }^{1}$ Graduate student Department of physiology Saveetha Dental College, Saveetha \\ Institute of Medical and Technical Sciences (SIMATS) Saveetha University, Chennai, India \\ ${ }^{2}$ Assistant Professor Department of physiology Saveetha dental college, Saveetha Institute \\ of Medical and Technical Sciences (SIMATS) Saveetha University, Chennai, India. \\ ${ }^{3}$ Assistant Professor Department of physiology Saveetha dental college, Saveetha Institute \\ of Medical and Technical Sciences (SIMATS) Saveetha University, Chennai, India
}

\begin{abstract}
Haemophobia is generally defined as an irrational fear of blood. It is usually caused because of trauma experienced during childhood days. The basic symptoms of haemophobia includes sweating profusely, trouble in breathing, feeling nauseated around blood or injury, etc. Trypanophobia is the extreme fear of procedures involving needles or injections. This phobia can be learned or inherited. The main aim of the study is to assess the awareness about the haemophobia and trypanophobia among out-patients of Saveetha Dental College \& Hospitals. A self administrated questionnaire comprising 10 questions was created with the help of a survey-planet website. A survey was created and was circulated among 100 dental patients and the responses were recorded in the form of graphs and pie charts. It was observed that trypanophobia \&t haemophobia were two prevalent fears persisting among almost all age groups. Almost 1/4th of the patients who were surveyed had negative childhood experiences related to blood and injections. From this survey, it is evident that haemophobia and trypanophobia may not seem to be very evidently observed among dental patients, it is important to treat and find a solution for such irrational fears.
\end{abstract}

\section{KEY WORDS: HAEMOPHOBIA, TRYPANOPHOBIA, DENTAL PATIENTS, FEAR.}

\section{INTRODUCTION}

Haemophobia and Trypanophobia are two different types of fears which are categorised as irrational kinds of fears. Haemophobia, commonly known as blood phobia, is an extreme, irrational and excessive fear of

\section{ARTICLE INFORMATION}

*Corresponding Author: gayatri.physio88@gmail.com Received 30th July 2020 Accepted after revision 24th Sep 2020 Print ISSN: 0974-6455 Online ISSN: 2321-4007 CODEN: BBRCBA

Thomson Reuters ISI Web of Science Clarivate Analytics USA and Crossref Indexed Journal

\section{Clarivate
Analytics}

NAAS Journal Score 2020 (4.31) SJIF: 2020 (7.728)

A Society of Science and Nature Publication,

Bhopal India 2020. All rights reserved.

Online Contents Available at: http//www.bbrc.in/

Doi: http://dx.doi.org/10.21786/bbrc/13.8/183 blood (Ditto et al., 2012). This is classified as a part of the subtype "blood-injection-injury" phobia (BII phobia). This sub-type also includes the other recurrent phobia, i.e., trypanophobia, otherwise known as fear of needles. Most types of specific phobias can cause an increase in heart rate \&t blood pressure. This can also instigate other symptoms like fainting on the sight of blood.

The blood-injection- injury phobia is found to be prevalent in only $3-4 \%$ of the general population (Wani et al., 2014). It has also been observed that this phobia occurs more often in younger age groups and less educated groups of the society (LeBeau et al., 2010). These phobic individuals, as a result, avoid hospitals, frequent dental check-ups and vaccinations, which can have adverse side-effects (Selvi et al., 2020). Both these phobias- haemophobia

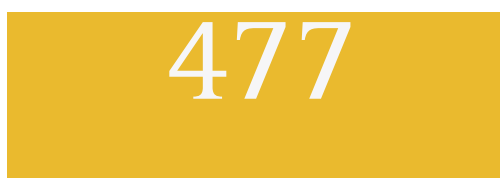


A trypanophobia are closely interconnected to dental phobia. The main root cause of these phobias is still not clearly understood. Researchers have identified that this may be an effect or outcome of genetic underpinnings or due to some traumatic experience that they must have been through in early stages of childhood (Page, 1994). Dental patients usually fear visiting dental hospitals due to the fear of being pricked by the doctor for application of local anaesthesia (Prabu, n.d.).

Symptoms exhibited by haemophobia and trypanophobia are roughly the same (Barlow and Ellard, 2018). The BII phobia involves symptoms such as turning pale, occurrence of profuse sweating, nausea and it might cause cardiac arrest in worst cases (Ayala et al., 2010). Various studies and researches conducted by our team (Fathima and Preetha, 2016)(Rj and R, 2016)(Iyer et al., 2019)(David et al., 2019)(Shruthi and Preetha, 2018) (Samuel and Devi, 2015) (Baheerati and Gayatri Devi, 2018)(Harsha et al., 2015)(Dave and Others, 2016)(Priya et al., 2019) (R and Sethu, 2018)(Swathy and Gowri Sethu, 2015)(Timothy et al., 2019). There is a lack in this current study. So the main aim of this study is to assess the awareness about the haemophobia and trypanophobia among out-patients in dental hospitals.

\section{MATERIAL AND METHODS}

This cross-sectional survey based-study setting was done through an online survey, among the dental patients of Saveetha Dental College. The usage of online surveys is time-saving $\mathrm{Ct}$ also involves a varied number of people. There were 100 participants involved in the survey. The sampling was done by the simple random sampling method. A questionnaire comprising 10 questions was posted on the online survey platform. The questionnaire validity checking was performed by consulting an expert. The data collection was done through Google forms and the data manipulation through MS Excel. The data obtained was plotted in the form of pie charts \& t bar graphs. Age and education were considered as independent variables whereas awareness about haemophobia and trypanophobia about it were in the list of dependent variables. Descriptive analysis and the correlation analysis by Chi square test was analysed using SPSS software.

Figure 1: The pie chart represents the distribution of gender. The red colour denotes male and blue colour denotes female. Majority of the participants were females (62\%).

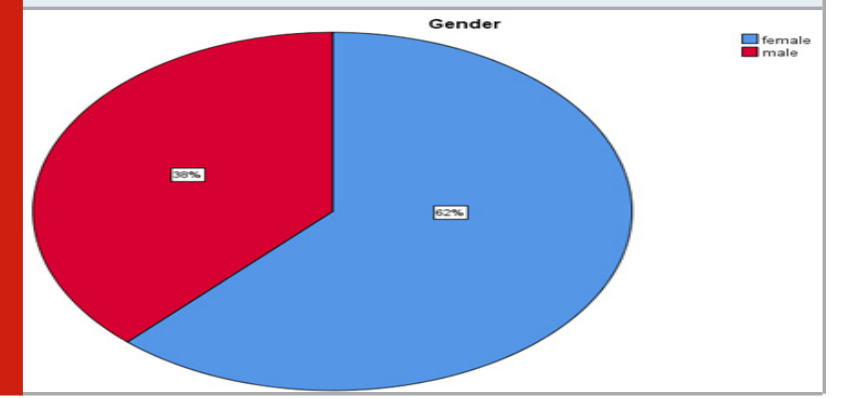

478

\section{RESULTS AND DISCUSSION}

In the present conducted study, the responses for each question were plotted and sketched in the form of pie-charts. The questions were basically categorised into three sub-parts: 4 general questions; 3 questions related to haemophobia; \& 3 questions associated with trypanophobia. When enquired about the negative childhood experiences they have had with blood, 89\% of the patients responded positively. Also, most of the patients have implied that they did not face any panic attacks or fear on the sight of needles, blood, or any other dental instruments placed ahead of them. $76 \%$ of the out-patients assume that these phobias are all irrational kinds of fear. In addition to that, the majority of the patients believe that this phobia can be treated.

Figure 2: The pie chart represents the distribution of fear of dentists among participants. Red colour represents yes and blue colour represents no. Majority of the participants have responded positively (63\%).

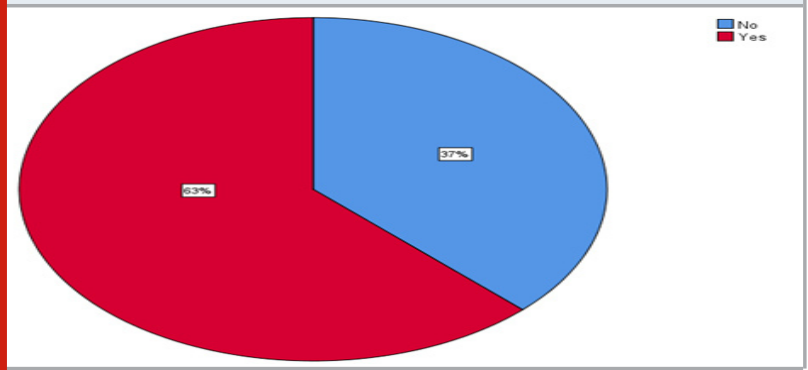

Figure 3: The pie chart represents the distribution of fear of extracting teeth among participants. Red colour represents yes and blue colour represents no. Majority of the participants have responded affirmatively (80\%).

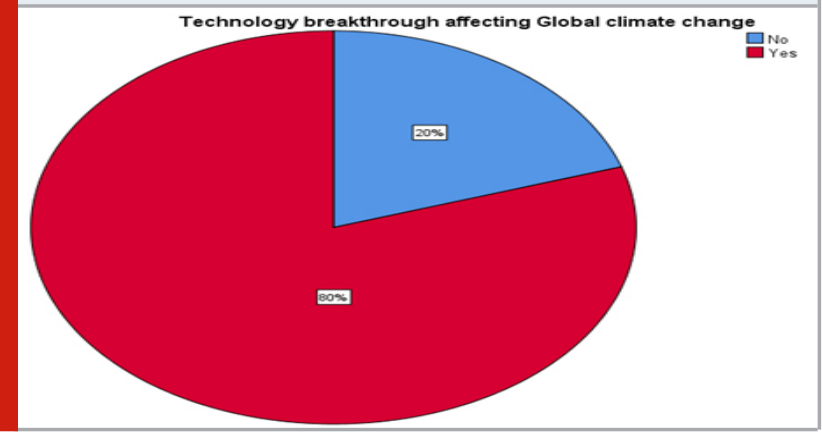

When inquired about the prevalence of fear of dentists among the participants, $62 \%$ of females and 38\% of males participated in this study (figure 1). 63\% of the participants responded affirmatively (Figure 2). It was observed that $80 \%$ of the participants had fear of getting their tooth extracted (Figure 3). 85\% of the dental patients feel dizzy on the sight of blood (Figure 4). $89 \%$ of the participants have had negative experiences related to blood in their childhood. (Figure 5). 76\% of the respondents think that this phobia is an irrational type of fear (Figure 6). 70\% of the participants of the survey have family members who are phobic to injections and 
syringes (Figure 7). Majority of the participants have stated that they face anxiety or panic attacks on the sight of dental instruments or syringes (Figure 8). 63\% of the dental patients assume that these types of phobias can be treated (Figure 9). The association between gender and the link between the prevalence of fear of dentists among patients was found, with the help of Chi square test. $\mathrm{p}$ is statistically more than 0.05 , which is insignificant (Figure 10).

Figure 4: The pie chart represents the distribution of patients feeling dizzy on the sight of blood. Red colour represents yes and blue colour represents no. Most of the patients in the dental hospital have responded positively (85\%).

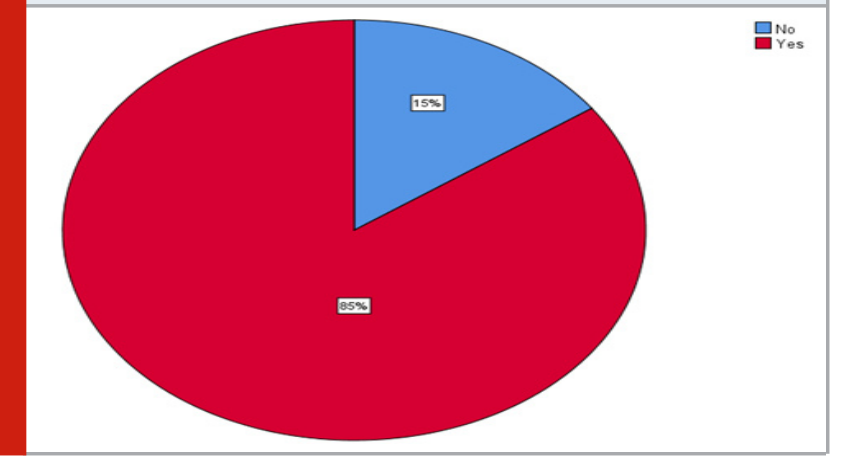

Figure 5: The pie chart represents the distribution of participants who had negative experiences related to blood during their childhood days. The red colour represents yes and blue colour represents no. Majority of the participants have responded positively (89\%).

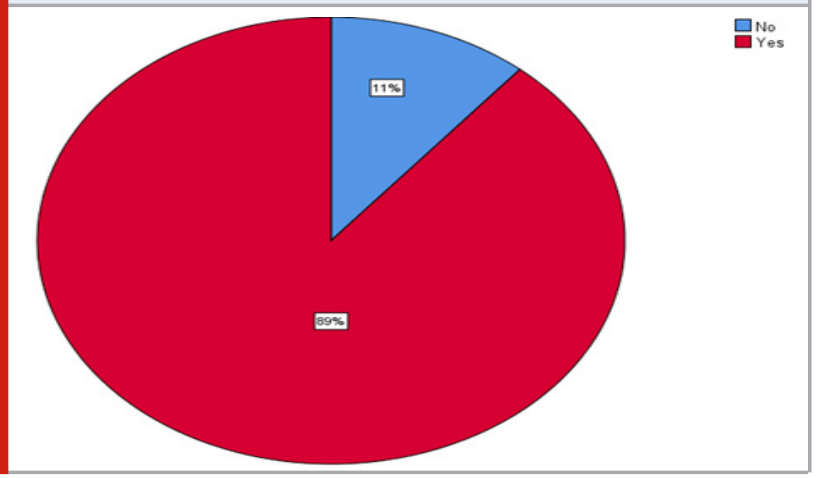

Figure 6: The pie chart represents the distribution of participants who think this fear is irrational or rational. The red colour represents irrational and blue colour represents rational. Majority of the participants have responded that this fear is irrational $(76 \%)$.

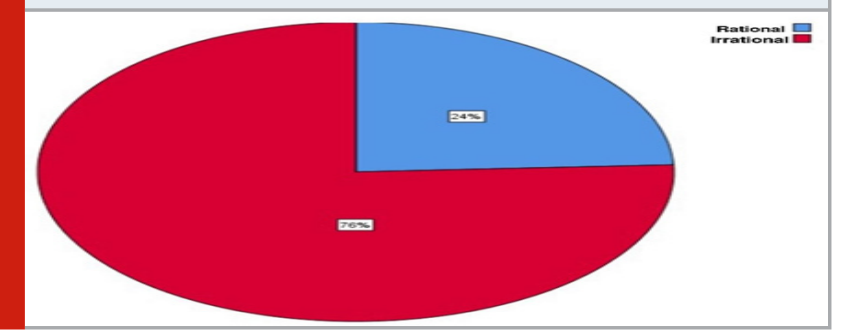

Figure 7: The pie chart represents the distribution of participants who have family members or friends who have fear of injections and syringes. The red colour represents yes and blue colour represents no. Majority of the patients have responded positively $(70 \%)$.

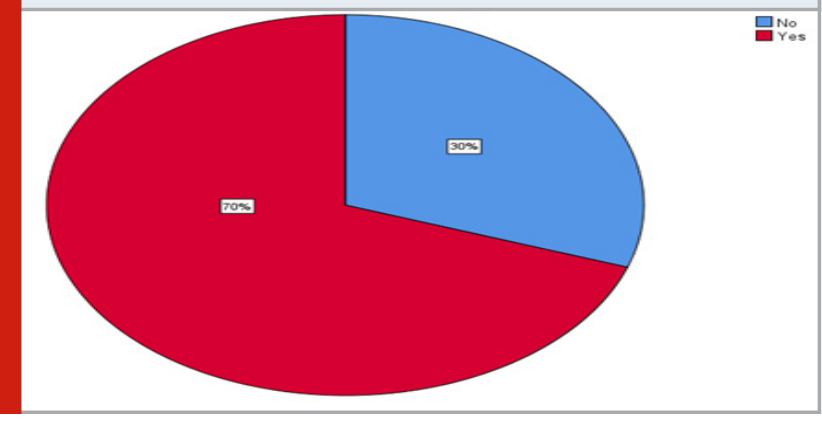

Figure 8: The pie chart represents the distribution of dental patients who face any anxiety or panic attacks on the sight of needles or injections. The red colour represents yes and blue colour represents no. Majority of the patients have responded positively (96\%).

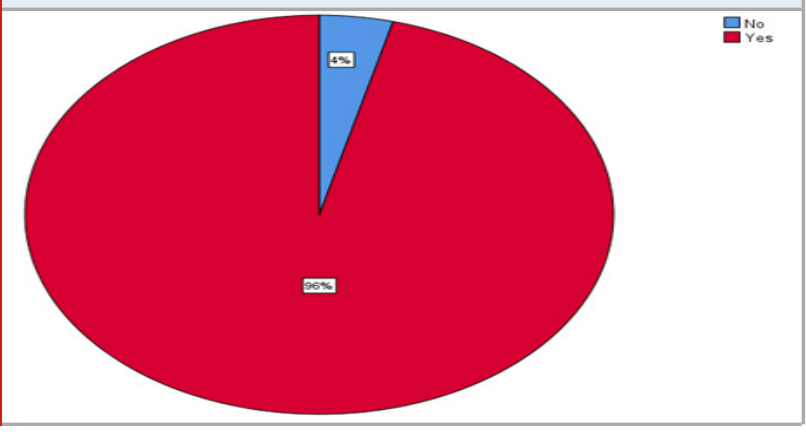

Figure 9: The pie chart represents the distribution of participants who think this phobia can be treated. The red colour represents yes and blue colour represents no. Majority of the patients have responded positively (63\%).

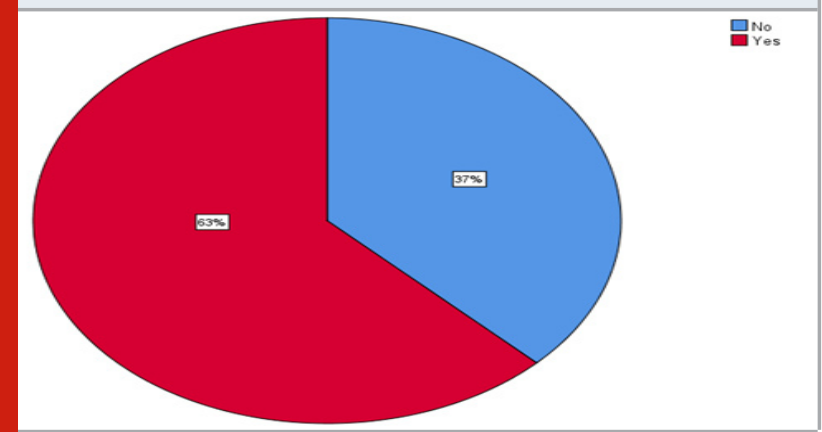

Similarly, the association between gender and the dental patients who have had negative experiences with blood during their childhood was determined, and $\mathrm{p}$ is statistically more than 0.05 and hence is insignificant (Figure 11). When comparing the present study, some researchers and analysts had described the duration in which the phobia lasts (Bienvenu and Eaton, 1998). The lifetime prevalence of this phobia was only 3.5\%. 
Subjects with blood-injection-injury phobia had higher lifetime histories of fainting and seizures than those without. They also observed that prevalence of BII phobia was comparatively lower in elderly and higher in females and less-educated people.

Figure 10: The bar graph depicts the association between gender and the prevalence of fear of dentists among participants. The $\mathrm{X}$-axis represents gender and $\mathrm{Y}$-axis represents the number of responses. The blue colour code denotes no and red denotes yes. Females had more fear of dentists than males. Pearson chi square test shows $p$ value is $0.847(>0.05)$, which is statistically not significant.

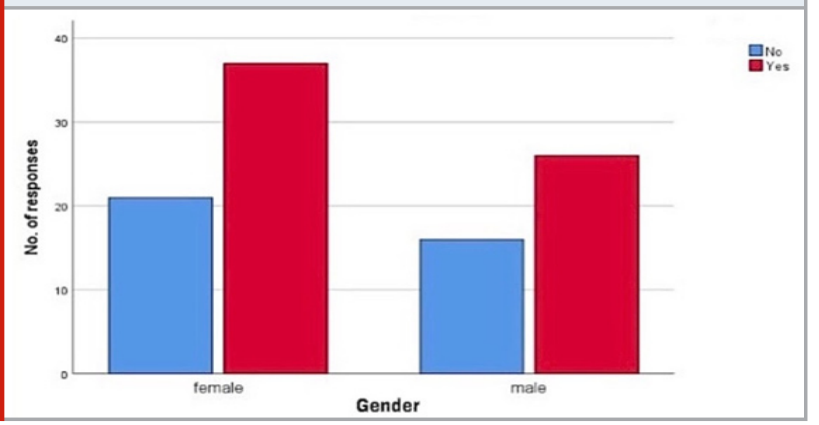

Figure 11: The bar graph depicts the association between gender and the dental patients who have had negative experiences with blood during their childhood days. The $\mathrm{X}$-axis represents gender and $\mathrm{Y}$-axis represents the number of responses. The blue colour code denotes no and red denotes yes. Females had more negative experiences related to blood than men. Pearson chi square test shows $p$ value is $0.090(>0.05)$, which is statistically not significant.

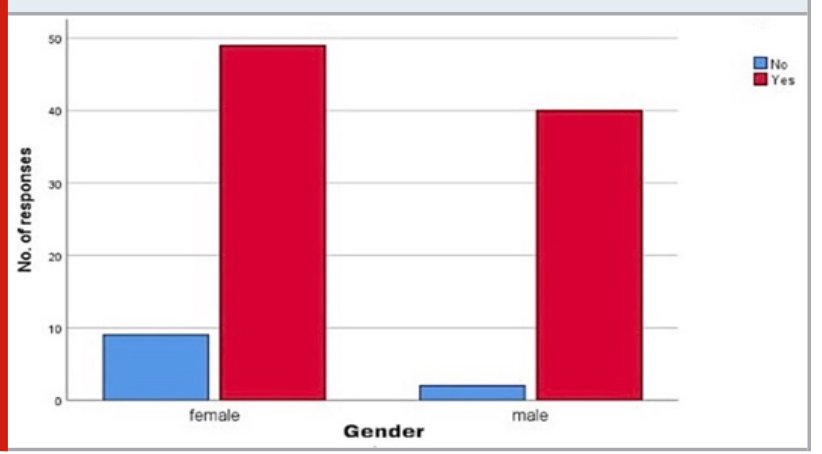

On the contrary, few others conducted research about the prevalence of blood and injection phobia among pregnant women (Lilliecreutz and Josefsson, 2008). They had observed that this phobia seemed to be relatively common and felt that it had to be recognised so as to avoid a great deal of discomfort and fear among pregnant women. Another study identified two phases of BII phobia, which is called a biphasic (or) a two-phase response of fainting (Agras et al., 1969). In the first phase, the phobic individual experiences anxiety, which leads to an increase in heart rate and blood pressure, which in turn causes the activation of the sympathetic nervous system. In contrast to this, the second phase results in a drop in heart rate, as mentioned before, or the vasovagal response, which is triggered by the vagus nerve as a part of the parasympathetic nervous system (Ritz et al., 2010).

\section{CONCLUSION}

From this survey, it revealed that prevalence of such fears is not much common among dental patients. Though it does not seem to be dreadful in the first place, it proves to be dangerous when present with other medical disorders.

\section{ACKNOWLEDGEMENTS}

The authors would like to acknowledge the help and support rendered by the study participants for the accomplishment of the study.

Conflict of Interest: None declared.

\section{REFERENCES}

Agras S, Sylvester D and Oliveau D (1969) The epidemiology of common fears and phobia. Comprehensive psychiatry 10(2): 151-156.

Ayala ES, Meuret AE and Ritz T (2010) Confrontation with blood and disgust stimuli precipitates respiratory dysregulation in blood-injection-injury phobia. Biological psychology 84(1): 88-97.

Baheerati MM and Gayatri Devi R (2018) Obesity in relation to Infertility. Research Journal of Pharmacy and Technology. DOI: 10.5958/0974-360x.2018.00585.1.

Barlow DH and Ellard KK (2018) Anxiety and related disorders. General Psychology 18: 178.

Bienvenu OJ and Eaton WW (1998) The epidemiology of blood-injection-injury phobia. Psychological medicine. cambridge.org. Available at: https://www.cambridge. org/core/journals/psychological-medicine/article/ epidemiology-of-bloodinjectioninjury-phobia/44B260 3FC1218AF52BC8F5256A853837.

Dave PH and Others (2016) Pathogenesis and Novel Drug for Treatment of Asthma-A Review. Research Journal of Pharmacy and Technology 9(9). A \& V Publications: 1519-1523.

David, David, Jothi Priya A, et al. (2019) Physical Fitness among the Dental Physician, Dental Undergraduates and Postgraduates Students. Indian Journal of Public Health Research \& Development. DOI: 10.5958/09765506.2019.02801.8.

Ditto B, Gilchrist PT and Holly CD (2012) Fear-related predictors of vasovagal symptoms during blood donation: it's in the blood. Journal of Behavioral Medicine. DOI: 10.1007/s10865-011-9366-0.

Fathima F and Preetha P (2016) EVALUATION OF THYROID FUNCTION TEST IN OBESE PATIENTS. Asian Journal of Pharmaceutical and Clinical Research. DOI: 10.22159/ajpcr.2016.v9s3.12959.

Harsha L, Priya J, Shah KK, et al. (2015) Systemic approach to management of neonatal jaundice and 
prevention of kernicterus. Research Journal of Pharmacy and Technology 8(8). A \& V Publications: 1087-1092. Iyer PK, Gayatri Devi R and Jothi Priya A (2019) A Survey Study on Causes, Treatment and Prevention of Onychocryptosis. Indian Journal of Public Health Research \& Development. DOI: 10.5958/09765506.2019.01990.9.

LeBeau RT, Glenn D, Liao B, et al. (2010) Specific phobia: a review of DSM-IV specific phobia and preliminary recommendations for DSM-V. Depression and Anxiety. DOI: 10.1002/da.20655.

Lilliecreutz C and Josefsson A (2008) Prevalence of blood and injection phobia among pregnant women. Acta obstetricia et gynecologica Scandinavica. Taylor \& Francis. Available at: https://www.tandfonline.com/ doi/abs/10.1080/00016340802468324.

Page A (1994) Blood-injury phobia. Clinical Psychology Review. DOI: 10.1016/0272-7358(94)90036-1.

Prabu D (n.d.) FACTORS DETERMINING ANXIETY IN PATIENTS UNDERGOING TOOTH EXTRACTION. Available at: http://www.ijsdr.org/papers/IJSDR2002049. pdf.

Priya J, Devi G and Others (2019) Evaluation of Muscular Endurance among Dentists. Indian Journal of Public Health Research \& Development 10(10). Available at: http://search.ebscohost.com/login.aspx?direct=true\&tp rofile $=$ ehostCtscope $=$ siteCtauthtype $=$ crawlerEtjrnl=097 $60245 \mathrm{ctAN}=140756206 \mathrm{cth}=\mathrm{G} 4 \mathrm{SC} \% 2 \mathrm{FJ} 8 \mathrm{z} \% 2 \mathrm{BUHFuuT}$ bV4UFDCYnk6MKUTskQkH7kGxLd3EgnLZ4lb\%2FVD EMrZPtKML9s6AouBNijcz\%2BNcfv3UaNBkw\%3D\%3 Detcrl $=\mathrm{c}$.

R GD and Sethu G (2018) EVALUATION OF ADENOIDS BY ORONASAL AND NASAL SPIROMETRY. Asian
Journal of Pharmaceutical and Clinical Research. DOI: 10.22159/ajpcr.2018.v11i10.27365.

Ritz T, Meuret AE and Ayala ES (2010) The psychophysiology of blood-injection-injury phobia: looking beyond the diphasic response paradigm. International journal of psychophysiology: official journal of the International Organization of Psychophysiology 78(1): 50-67.

$\mathrm{Rj}$ I and R GD (2016) Role of environmental factors on sleep patterns of different age groups. Asian Journal of Pharmaceutical and Clinical Research. DOI: 10.22159/ ajpcr.2016.v9i6.13832.

Samuel AR and Devi MG (2015) Geographical distribution and occurrence of Endemic Goitre. Research Journal of Pharmacy and Technology 8(8). A \& V Publications: 973-978.

Selvi VT, Devi RG and Jothipriya A (2020) Prevalence of dental anxiety among the OP patients in Saveetha Dental College. Drug Invention Today 14(1).

Shruthi M and Preetha S (2018) Effect of Simple Tongue Exercises in Habitual Snorers. Research Journal of Pharmacy and Technology 11(8). A \& V Publications: 3614-3616.

Swathy S and Gowri Sethu V (2015) Acupuncture and lower back pain. Research Journal of Pharmacy and Technology. DOI: 10.5958/0974-360x.2015.00165.1.

Timothy CN, Gayatri Devi R and Jothi Priya A (2019) Evaluation of Peak Expiratory Flow Rate (PEFR) in Pet Owners. Indian Journal of Public Health Research \& Development. DOI: 10.5958/0976-5506.2019.01989.2. Wani AL, Ara A and Bhat SA (2014) Blood injury and injection phobia: the neglected one. Behavioural neurology 2014: 471340. 